\title{
Comunicação como ritual (James Carey) e folkcomunicação (Luiz Beltrão): modelos teóricos na interface com a cultura
}

Yuji Gushiken*

DOI: https://doi.org/:10.33571/revistaluciernaga.v12n23a1

\section{Resumo}

O artigo apresenta uma interpretação de dois modelos teóricos na emergência do campo científico comunicacional: a visão ritual da comunicação, do americano James Carey, e a folkcomunicação, do brasileiro Luiz Beltrão. Os dois modelos são construídos tendo como condição histórica as nuances dos campos culturais nos EUA e no Brasil na segunda metade do século XX.

A hipótese de trabalho é que os modelos demandam renegociações epistemológicas no campo científico da comunicação, na medida em que sugerem um distanciamento do paradigma tecnológico constituído pela moderna comunicação massiva e do modelo da comunicação como difusão de informações. As práticas interdisciplinares de pesquisa promoveram uma abertura para abordagens teóricas ligadas ao campo da cultura, enquadrando objetos e temas de pesquisa segundo distintas dinâmicas culturais nos EUA e no Brasil.

O estudo comparado dos modelos de James Carey e Luiz Beltrão fornece pistas para discussões sobre as constantes mudanças em processos comunicacionais na modernização capitalista, os conceitos de mídia segundo padrões de desenvolvimento socioeconômico, a abrangência do campo comunicacional e as virtualidades da pesquisa interdisciplinar entre comunicação e cultura.

Palavras chave: Comunicação; comunicação como ritual; folkcomunicação; modelos teóricos.

Recebido. Fevereiro 07, $2020 \quad$ Aceitado. Fevereiro, 18, 2020

*Professor do Curso de Comunicação Social e do Programa de Pós-Graduação em Estudos de Cultura Contemporânea da Universidade Federal de Mato Grosso (PPGECCO-UFMT/ Cuiabá). Doutor em Comunicação e Cultura pela Universidade Federal do Rio de Janeiro (UFRJ). Researcher at Posgraduation Program in Contemporary Culture Studies (ECCO).

Orcid: http://orcid.org/0000-0002-6620-3375; ; e-mail: yug@uol.com.br 


\title{
Communication as ritual (James Carey) and folkcommunication (Luiz Beltrão): theoretical models at the interface with culture
}

\author{
Yuji Gushiken*
}

DOI: https://doi.org/: 10.33571/revistaluciernaga.v12n23a1

\begin{abstract}
The article presents an interpretation of two theoretical models in the emergence of the communicational scientific field: the ritual vision of the communication, of the American James Carey, and the folkcommunication, of the Brazilian Luiz Beltrão. The two models are constructed having as a historical condition the nuances of the cultural fields in the USA and Brazil in the second half of the twentieth century.
\end{abstract}

The working hypothesis is that the models demand epistemological renegotiations in the scientific field of communication, insofar as they suggest a distancing from the technological paradigm constituted by modern mass communication and the model of communication as information diffusion. The interdisciplinary practices of research promoted an openness to theoretical approaches related to the field of culture, framing objects and themes of research according to different cultural dynamics in the USA and Brazil.

The comparative study of the models by James Carey and Luiz Beltrão provides clues to discussions about the constant changes in communication processes in capitalist modernization, media concepts according to patterns of socioeconomic development, the comprehensiveness of the communication field and the interdisciplinary research possibilities between communication and culture.

Keywords: Communication; ritual view; folkcommunication; theoretical models.

Received. February 07, 2020

Accepted. February18,2020

\footnotetext{
* Professor of the Social Communication Course and the Postgraduate Program in Contemporary Culture Studies at the Federal University of Mato Grosso (PPGECCO-UFMT I Cuiabá). PhD in Communication and Culture from the Federal University of Rio de Janeiro (UFRJ). Researcher at the Postgraduate Program in Contemporary Culture Studies (ECCO). Orcid: http://orcid.org/0000-0002-6620-3375; e-mail: yug@uol.com.br
} 


\section{La comunicación como ritual (James Carey) y la folkcomunicación (Luiz Beltrão): modelos teóricos en la interfaz con la cultura}

Yuji Gushiken*

DOI: https://doi.org/:10.33571/revistaluciernaga.v12n23a1

Resumen

El artículo presenta una interpretación de dos modelos teóricos en el surgimiento del campo de la ciencia de la comunicación: la visión ritual de la comunicación, del estadounidense James Carey, y folkcomunicación, del brasileño Luiz Beltrão. Los dos modelos se construyen teniendo como condición histórica los matices de los campos culturales de EE.UU y Brasil en la segunda mitad del siglo $\mathrm{XX}$.

La hipótesis de trabajo es que los modelos exigen renegociaciones epistemológicas en el campo científico de la comunicación, en la medida en que sugieren un alejamiento del paradigma tecnológico constituido por la comunicación de masas moderna y del modelo de comunicación como difusión de la información. Las prácticas de investigación interdisciplinaria promovieron una apertura a los enfoques teóricos vinculados al campo de la cultura, enmarcando los objetos y los temas de investigación de acuerdo con las diferentes dinámicas culturales de los Estados Unidos y el Brasil.

El estudio comparativo de los modelos de James Carey y Luiz Beltrão proporciona pistas para el debate sobre los constantes cambios en los procesos de comunicación en la modernización capitalista, los conceptos de los medios de comunicación según las pautas del desarrollo socioeconómico, el alcance del campo de la comunicación y las virtualidades de la investigación interdisciplinaria entre la comunicación y la cultura.

Palabras clave: Comunicación; comunicación como ritual; folkcomunicación; modelos teóricos.

Recibido. Febrero 07, $2020 \quad$ Aceptado. Febrero 18. 2020

*Profesor del Curso de Comunicación Social y del Programa de Postgrado en Estudios de Cultura Contemporánea de la Universidad Federal de Mato Grosso (PPGECCO-UFMT/ Cuiabá). Doctorado en Comunicación y Cultura de la Universidad Federal de Río de Janeiro (UFRJ). Investigador del Programa de Posgrado en Estudios de Cultura Contemporánea (ECCO). Orcid: http://orcid.org/0000-0002-6620-3375; e-mail: yug@uol.com.br 


\section{Introdução}

A comunicação como ritual (visão ritual da comunicação), do americano James Carey, e a folkcomunicação, do brasileiro Luis Beltrão, são propostas de dois modelos teóricos que têm em comum o fato de se inserirem em uma jovem tradição de pesquisa em Comunicação, principalmente nas universidades brasileiras, onde o processo de institucionalização das práticas de pesquisa torna-se mais visível apenas a partir da década de 1970, com o funcionamento dos primeiros cursos de pós-graduação stricto sensu na área e a maior amplitude da rede científica no país, através do Sistema Nacional de Pós-Graduação (SNPG). Os dois modelos teóricos fazem contraponto às práticas midiáticas que caracterizam o modelo da comunicação, hegemônico desde o século XX, como sinônimo de "transmissão de informação", que no campo dos estudos antropológicos tem como referência os processos de difusionismo cultural.

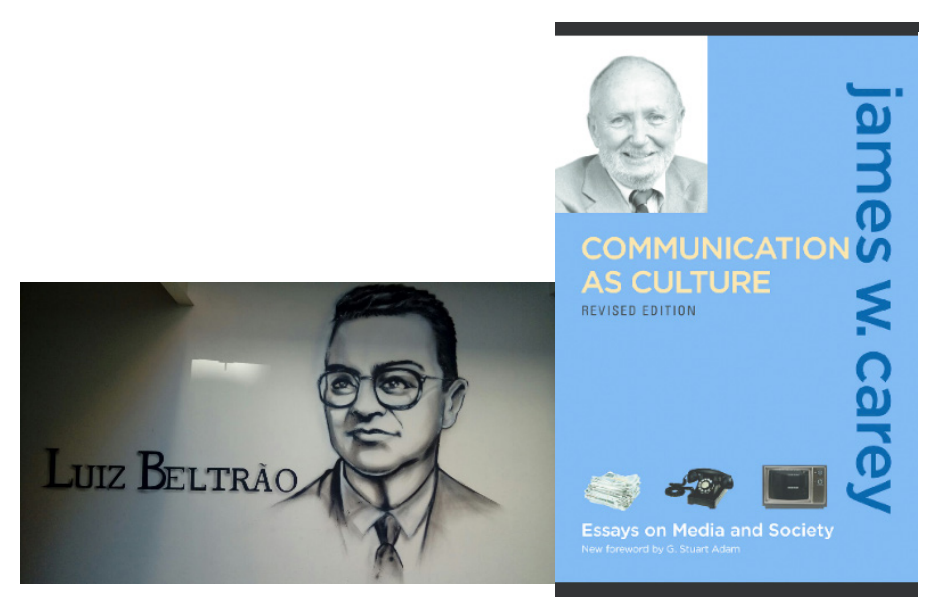

No campo da pesquisa em comunicação, a emergência dos modelos teóricos de James Carey e de Luiz Beltrão torna mais complexa a definição e a delimitação disciplinar do que se configura historicamente como um campo de estudos e pesquisa, o campo comunicacional, uma vez que os dois modelos teóricos sugerem a apropriação e o enquadramento de novos objetos de pesquisa na área instituída, o que inclui dinâmicas comunicacionais de práticas culturais.

Historicamente, o campo da comunicação no Brasil, entre abordagens científicas e filosóficas, tem buscado sua constituição "disciplinar" na organização institucional das práticas de pesquisa, o que inclui a criação de entidades científicas e programas de pós-graduação. A criação de uma disciplina da Comunicação, no entanto, emergiu historicamente em duas instâncias através de duas práticas: o ensino de graduação nos cursos de Comunicação Social e a realização de pesquisas sobre questões comunicacionais a partir de outras áreas do conhecimento.

Em outras áreas do conhecimento, de modo incisivo nas Ciências Sociais e Humanas, mas também nas Letras e na Filosofia, práticas comunicacionais, em especial práticas midiáticas, têm sido consideradas como objetos de estudos - caso, por exemplo, da emergência, no século XX, da sociologia da comunicação e da psicologia da comunicação. A partir de distintas interfaces teóricas, a pesquisa em comunicação tem se caracterizado propriamente como práticas interdisciplinares, 0 que já fornecia indícios de sua abrangência e a conseqüente dificuldade na definição e delimitação do campo de investigação numa convergência idealizadamente disciplinar.

Neste artigo, promove-se uma leitura de James Carey e Luiz Beltrão, dois autores do moderno pensamento comunicacional na América do Norte (Carey) e América do Sul (Beltrão), sem, contudo, 
pretender esgotá-los em sua complexidade e minúcias conceituais. Busca-se, porém, de modo analítico e comparativo, esboçar aproximações entre enunciados presentes nos dois modelos teóricos e, de modo simultâneo, evidenciar o afastamento que ambos promovem com relação à pesquisa em comunicação de massa.

Assim, o artigo analisa como a visão ritual (James Carey) e a folkcomunicação (Luiz Beltrão) tornaram-se perspectivas teóricas que fizeram diferença ao produzirem um afastamento com relação aos hegemônicos estudos da comunicação de massa, até então foco primordial de interesse nas ciências da comunicação emergentes ao longo do século XX, em sua experiência de modernização industrial e transformações nas tecnologias midiáticas.

A conseqüência mais visível é que os modelos de Carey e de Beltrão atribuem nova amplitude à pesquisa em comunicação na segunda metade do século XX, tendo como questão as dinâmicas comunicacionais presentes no âmbito das práticas culturais. Analisa também as implicações que essas duas perspectivas apresentam nos planos teórico-metodológico e epistemológico quando o tema de estudos e a relação muito próxima entre comunicação e cultura.

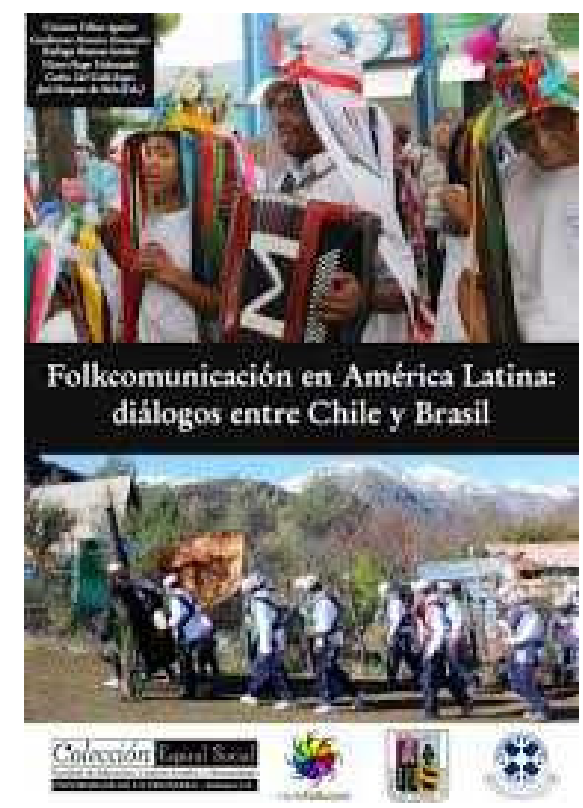

\section{Visão ritual: dimensões comunicacionais da cultura americana}

Nos EUA, de onde se originou a tradição de estudos em comunicação como ciência do comportamento, na interface com as ciências sociais e humanas, James Carey, a partir de leituras do filósofo e educador liberal John Dewey, propôs uma revisão nos fundamentos teóricos da área. Segundo Carey (1992), há duas concepções de comunicação que permeiam a cultura americana: a visão transmissiva e a visão ritualística. As duas concepções de comunicação têm origens no campo religioso, ainda que se refiram a diferentes regiões da experiência mística. A visão de comunicação mais comum na cultura americana é a transmissiva, definida por termos como "transferência" (imparting), "envio" (sending), "transmissão" (transmitting) ou "dar informação a outros" (giving information to others). (CAREY: 1992, p. 15). [1] 
Não por acaso, boa parte da pesquisa em comunicação de massa (mass communication research) emerge historicamente marcada por ter como foco de interesse o pensamento comunicacional como prática difusionista: a concepção de comunicação como transmissão linear de informação que caracteriza não apenas o imaginário cultural americano, mas o próprio imaginário cultural do Ocidente moderno.

Interessa, neste artigo, mais especificamente a visão ritualística proposta por James Carey. A comunicação como ritual - concebida, portanto, numa abordagem cultural - é considerada "arcaica" por resistir à força dos processos de modernização ao longo do século XX. A visão ritual da comunicação liga-se a termos correlatos como "compartilhamento" (sharing), "participação" (participation), "associação" (association), "camaradagem" (fellowship) e "detenção de uma fé comum (the possession of a common faith)". Explora a "identidade" (identity) e as "raízes comuns" (common roots), com base em termos e noções afins como "comum, ordinário" (commonness), "comunhão" (communion), "comunidade" (community) e "comunicação" (communication). (CAREY: 1992, p. 18)

Na visão ritual da comunicação, o mundo cultural comunitário é criado através de formas materiais. Atividades sociais e lúdicas - como danças, jogos, notícias (news stories) e "sermões" (speeches) [2] - são narrativas que, em certa medida, servem de controle e recipiente para a ação humana. Carey define a visão ritual da comunicação como aquela "direcionada não para a extensão de mensagens no espaço, mas em direção à manutenção da sociedade no tempo; não o ato de transmitir informação, mas a representação de crenças compartilhadas" [3]. (CAREY: 1992, p. 1819 , tradução nossa)

A construção teórica de Carey é a de que os processos comunicacionais relacionam-se diretamente com o campo da cultura em dois momentos no que se refere à produção de linguagem. Num primeiro momento, as formas simbólicas apresentam o mundo (são "símbolos de" algo) e num segundo momento tais formas criam a realidade que apresentam (são "símbolos para"). Assim, estudar comunicação, conforme Carey, demanda examinar o atual processo social em que formas simbólicas significativas são criadas, apreendidas e usadas.

É nessas formas simbólicas que se produzem as interações humanas, em escalas distintas: interpessoais (no âmbito comunitário) ou massivas (mediadas pelos meios de comunicação). Assim, Carey desenvolve um pensamento comunicacional que não se resume à mera transmissão de informação, mas considera os sistemas socioculturais criados frente à realidade e os modos para representá-la como ambientes comunicacionais. Entre os sistemas socioculturais estão a arte, a ciência, o jornalismo, a religião, o senso comum e a mitologia (CAREY: 1992, p. 30). Esses sistemas de percepção e construção da realidade designam a relação direta entre comunicação e cultura na medida em que, como sugere o próprio autor, pode-se compreender a comunicação através de uma abordagem cultural. [4].

A comunicação, portanto, apresenta uma dimensão de construção histórica na medida em que é resultado também da "corrupção da cultura" que se cria e se revela a partir da natureza humana. $\mathrm{Na}$ historicidade da construção cultural, concebe-se que há comunicação enquanto houver aptidão para se construir modelos de representação da realidade social, mas que simultaneamente se constituem como a própria realidade social. Se a comunicação não se relaciona com atribuições da aptidão de base genética, cabe descobrir sistemas ou modelos cognitivos e expressivos no âmbito da cultura que apontem como o "milagre" da comunicação é realizado. 
Comunicação, como sugere Carey, relaciona-se com a produção de sentido, que por sua vez relaciona-se com a cultura em dimensão comunitária. A comunicação, para o cidadão comum, consiste em um conjunto de atividades meramente diárias: conversar, passar instruções, divertirse, sustentar um debate ou uma discussão, adquirir informação (CAREY: 1992, p. 33). Assim, diz Carey, nossas mentes e vidas são formatadas pela nossa experiência total, ou melhor, por representações de experiência, e um nome para essa experiência é comunicação.

Se os modelos de representação tornam-se opacos, a realidade, em conseqüência, torna-se inapreensível, e fica-se inapto a descrevê-la ou compartilhá-la. Essas opacidades são indícios de que há falhas no modelo de comunicação, compreendido, na sugestão de Carey, como a própria ambiência cultural onde as informações são produzidas e dotam-se ou não de sentido comum. Dito de outro modo, comunicação é menos transmissão e efeito de informações, e mais "drama" que dá forma, ordem e tom à vida social.

Carey sugere em seu texto uma lição. Ele argumenta que pensamos muito em sociedade como rede de poder, administração, decisão e controle - como uma ordem política. Ou então a pensamos como relações de propriedade, produção e comércio - uma ordem econômica. A proposta de Carey é perceber que a vida social vai além de poder e comércio, além de terapias. Com base em Williams, Carey sugere que a vida social "inclui compartilhamento de experiência estética, idéias religiosas, valores e sentimentos pessoais e noções intelectuais - uma ordem ritual” [5]. (CAREY: 1992, p. 34).

De modo mais preciso, o autor americano sugere uma definição de comunicação que ele mesmo considera de uma simplicidade desarmante, mas que detém algum poder e algum alcance intelectual: "comunicação é um processo simbólico pelo qual a realidade é produzida, mantida, reparada e transformada" [6]. (CAREY: 1992, p. 23). Um dos maiores problemas desta perspectiva teórica, segundo o próprio autor, é o fato de a comunicação referir-se à mais comum e mundana das experiências humanas.

Como se pode inferir no argumento de Carey, nada que se refere, até o momento em que ele formula o conceito, a segredos de técnicas de comunicação profissionais ou acesso a parafernálias tecnológicas da comunicação de massa. E nem necessariamente a ferramentas designadas modernamente de meios de comunicação, que, como já demonstrou a história da mídia e das teorias da comunicação, tornam-se elementos que constituem de modo mais enfático a centralidade da pesquisa em comunicação de massa.

Assim, o que está por baixo das ordens políticas e econômicas é a ordem ritualística, problematizada por Carey na medida em que a noção de cultura, na sociedade americana, tenha partido mais de um insistente individualismo típico do liberalismo da sociedade de consumo, não sendo por acaso que, como ele mesmo relembra, em geral a vida psicológica, centrada no indivíduo, seja colocada acima da realidade social.

$\mathrm{Na}$ abordagem cultural da comunicação, em especial na visão ritual, Carey reavalia a noção de cultura como crítica a uma visão puritana na qual se desvalorizam atividades humanas que não sejam pragmáticas ou orientadas para o mundo da economia e do trabalho. Ele situa, portanto, a visão ritual da comunicação como crítica da Modernidade, na medida em que esta reduz a noção de cultura aos constrangimentos dos processos econômicos e políticos. 

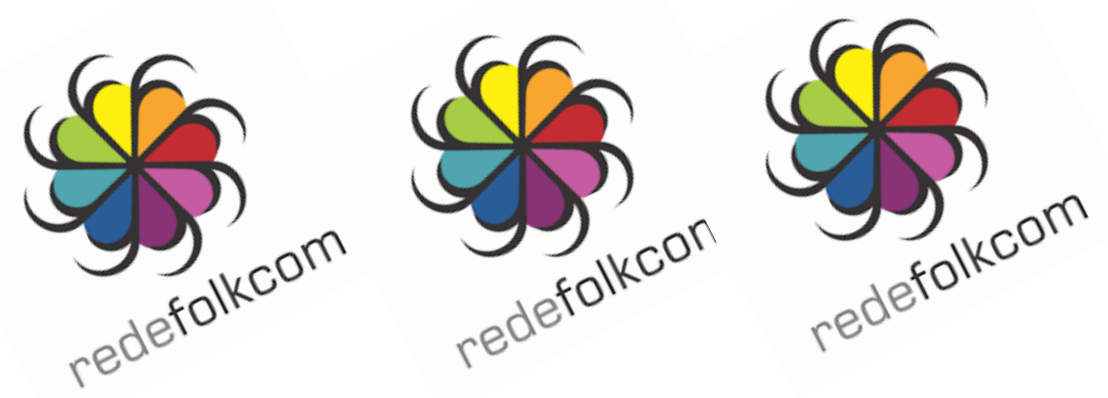

\section{Folkcomunicação: dimensões comunicacionais da cultura popular brasileira}

Folkcomunicação é um conceito de Luís Beltrão, jornalista e pesquisador pioneiro nas ciências da comunicação no Brasil. Designa as práticas sociais populares que põem em relação os sistemas folclóricos e outras instâncias de produção simbólica, o que inclui a indústria cultural e as práticas da cultura erudita. Nas condições socioeconômicas brasileiras, os segmentos populares caracterizamse historicamente pelo baixo índice de alfabetização, baixa renda econômica e baixa participação nos circuitos culturais hegemônicos.

Beltrão, depois de estudar a mídia moderna, em especial no campo jornalístico, buscou construir o conceito de folkcomunicação como sistema de comunicação no âmbito da cultura popular. Este sistema inclui o conjunto de agentes, meios, métodos e técnicas de que se valem os grupos marginalizados da sociedade na invenção de práticas comunicacionais para além das práticas consagradas da mídia comercial e das profissões socialmente instituídas da comunicação social (jornalismo, publicidade e propaganda, marketing, relações públicas, cinema).

Segundo Beltrão, folkcomunicação é, por natureza e estrutura, um processo artesanal e horizontal, semelhante em essência aos tipos de comunicação interpessoal, já que suas mensagens são elaboradas, codificadas e transmitidas em linguagens e canais familiares à audiência, por sua vez conhecida psicológica e vivencialmente pelo comunicador, ainda que dispersa (BELTRÃO: 2004, p. 74). Entre os modos de expressão e comunicação na folkcomunicação encontram-se a literatura, a arte, as crenças, os ritos, a medicina, os costumes em geral. Consideram-se ainda como veículos de comunicação populares aqueles entre produção artesanal e industrial: folhetos, volantes e atos de presença corporal.

Já na década de 1960, Luiz Beltrão considerava os sistemas de comunicação de massa - TV, rádio e jornal - como a ortodoxia da informação, por não serem exatamente representantes da opinião e dos ideais populares. Beltrão analisava, no âmbito das mestiçagens étnicas, como os "catimbós"(práticas ritualísticas do sincretismo religioso brasileiro) na região Nordeste do Brasil tornaram-se sistemas de produção e circulação de informações entre seus praticantes.

Num estudo posterior, Beltrão buscou caracterizar estas condições expressivas em âmbito popular como "comunicação dos marginalizados" como singularidade da folkcomunicação (BELTRÃO, 1980). Ainda que partindo da tradição da mass communication research americana, ele sugere uma ênfase geográfica, ao considerar características da cultura popular brasileira e o que, no âmbito das classes populares, ganha o rótulo da marginalização econômica e simbólica. 
Entram em cena os grupos sociais marginalizados, que vivem na transição entre a memória rural e a experiência urbana, atribuindo uma dimensão simultaneamente materialista e cultural à questão comunicacional.

O modelo teórico da folkcomunicação implicou, na medida de sua concepção por Beltrão, em adicionar objetos de investigação nas ciências da comunicação para além da pesquisa de comunicação com centralidade na mídia de massa, que compreende com maior ênfase as práticas comunicacionais legitimadas profissional e socialmente da publicidade, do jornalismo, das relações públicas, do rádio/televisão e do cinema.

O modelo teórico desenvolvido por Beltrão, portanto, promove uma interface direta entre comunicação e cultura, na medida em que o jornalista e professor brasileiro percebe, nas mais variadas expressões culturais populares, uma dinâmica comunicacional. O ethos social, portanto, funciona como um ambiente que captura e dispersa distintas formas de linguagem e promove a produção de sentido e as formas de vinculação social. A folkcomunicação, como conceito, aproximase do folclore na medida em que este se transforma, no processo de modernização midiática, em cultura popular.

No movimento que põe em relação folclore e cultura popular está o campo comunicacional. Folclore são as formas interpessoais ou grupais de manifestação cultural, protagonizadas pelas classes subalternas. Folkcomunicação, pelo menos num primeiro momento do pensamento comunicacional de Luiz Beltrão, é o uso de mecanismos artesanais de difusão simbólica para expressar, em linguagem popular, mensagens previamente veiculadas pela indústria cultural.

Entre as observações de Beltrão está a noção de que os segmentos populares têm meios próprios de expressão, e somente através deles é que podem entender a realidade e fazerem-se entender quando se trata de produção simbólica. Os agentes da comunicação popular usam meios expressivos já de uso corrente desde a época do Brasil Colônia. Entre estes meios inventados pelas demandas populares, Beltrão busca esquematizar as formas de expressão popular em folkcomunicação oral, escrita e opinativa.

Os agentes de informação oral compreendem, entre outros personagens, cantadores, caixeirosviajantes (representantes comerciais) e, mais recentemente, na modernização dos transportes, motoristas de caminhão. Na informação escrita incluem-se folhetos (literatura de cordel), almanaques e calendários. De forma análoga ao jornalismo opinativo, a folkcomunicação opinativa divide-se em centros de informação (a praça, a feira, o pátio das igrejas etc.), meios de expressão (imagéticos: sátira, caricatura, artesanato e artes plásticas populares; folguedos ou autos [7]. populares: queimado-Judas, serra-dos-velhos, mamulengo, bumba-meu-boi, carnaval. (BELTRÃO: 2001)

Na classificação proposta por Beltrão há inúmeras e variadas expressões na cultura popular brasileira que tornam-se estruturas simbólicas pelas quais as camadas populares dotam-se de possibilidades de produção de sentido. Para além do entendimento de mídia enquanto moderna tecnologia de envio e troca de informações, a cultura popular, no caso brasileiro, torna-se, ela própria, e simultaneamente, meio e mensagem numa estrutura que contém uma dinâmica caracterizadamente comunicacional.

Uma das contribuições de Beltrão às ciências da comunicação no Brasil foi ter adiantado, já no final dos anos 1960, a problematização nem tanto quanto aos efeitos da mídia, conforme a tradição dos estudos psicossociais da comunicação oriundos dos EUA (de modo específico, as primeiras fases 
da chamada mass communication research), mas quanto ao uso dos meios, deslocando o foco das pesquisas para o que posteriormente veio a ser designado, história das teorias da comunicação, como estudos de recepção.

Folkcomunicação, portanto, é uma construção teórica que, ao emergir no desenvolvimento das ciências da comunicação no Brasil, contribui na constituição de um campo de pesquisa justamente por considerar como temas e objetos de estudos distintas práticas socioculturais, compreendidas como fenômenos expressivos e comunicacionais no âmbito da cultura popular brasileira. De modo mais específico, trata-se de considerar uma dimensão comunicacional nas distintas expressões folclóricas, o que atribui à obra de Beltrão uma singularidade inovadora da pesquisa brasileira e mundial nas ciências da comunicação.

\section{Comunicação: Objetos culturais e comunicacionais}

A hipótese desenvolvida neste artigo é que a visão ritual, de James Carey, e a folkcomunicação, de Luiz Beltrão, emergiram como modelos teóricos que tornaram mais complexas as nuances metodológicas da pesquisa em comunicação como campo do conhecimento. Trata-se de uma questão que tem demandado um debate epistemológico, conforme se registra no campo comunicacional (PRADO, 2002; WEBER, BENTZ, HOHFELDT, 2002; TRINTA, POLITSCHUK, 2003; MARTINO: 2006;).

No Brasil, a pesquisa em comunicação foi constituída historicamente em práticas interdisciplinares de investigação, em especial a pesquisa em comunicação de massa a partir dos anos 1970. Trata-se de um período relevante no desenvolvimento da pesquisa brasileira da comunicação, caracterizada pela interface direta que manteve num primeiro momento com as ciências sociais e depois com outros campos, como as ciências da linguagem, originando distintos modelos de estudos da comunicação (LIMA, 2001).

A folkcomunicação, na virada da década de 1960 para 1970, e a visão ritual da comunicação, na década de 1980, refletiram, quase simultaneamente, o desenvolvimento de modelos teóricos que fizeram avançar a pesquisa nas ciências da comunicação em dois aspectos: 1) por fazerem diferença especificamente com relação à pesquisa em comunicação de massa, do qual podem ser considerados críticos e sucedâneos e 2) por buscarem constituir suas próprias singularidades como propostas de modelos teóricos, ao sugerirem a incorporação de novos objetos de estudos no que vinha sendo constituído como ciências da comunicação ao longo do século XX.

Nos dois modelos teóricos em questão, recuperam-se, principalmente, as dimensões interpessoais e comunitárias dos processos comunicacionais, em que as práticas comunicacionais não se resumem às práticas de consumo midiático e nem mídia se restringe ao conceito de mídia industrial de massa.

O trabalho teórico de Luiz Beltrão, como observador da cultura popular brasileira, foi propor na pesquisa em comunicação um recorte temático que compreende os processos de mediação entre folclore, cultura massiva e cultura erudita (BELTRÃO: 1991). Já o trabalho teórico de James Carey foi reconhecer uma "cultura de classe média", marcada principalmente por práticas de consumo na sociedade americana, para a qual a noção de cultura, a partir dos ambientes intelectuais, se relaciona com a noção de alta cultura, mas não se aplica a "propósitos domésticos" ou, como 
podemos interpretar com o autor, a banalidades do senso comum ordinário e cotidiano. (CAREY: 1992, p. 19)

Nos modelos teóricos do brasileiro Luiz Beltrão e do americano James Carey, como consequência da autorreflexividade própria do campo científico, atualiza-se uma reavaliação teórico-metodológica da pesquisa em comunicação. Esta reavaliação apresenta uma demanda pela ampliação e pelo enquadramento de novos objetos de estudos, conforme as singularidades de distintos ambientes culturais. Nas obras dos dois pesquisadores, trata-se da cultura popular brasileira e da cultura de classe média americana.

Quando esses novos objetos se enquadram na interface entre comunicação e cultura, convém lembrar que Beltrão cria sua perspectiva teórica com base em especial na cultura popular do Nordeste brasileiro; e Carey reconhece na cultura americana, tanto a científica quanto a do senso comum, a proeminência e a hegemonia da visão transmissiva da comunicação e, nas entrelinhas, uma cultura de consumo típica onde vigora a hegemonia do pensamento liberal.

O professor José Marques de Melo (BELTRÃO: 2004, p. 11) situa a folkcomunicação como uma disciplina em meio às então nascentes ciências da comunicação no Brasil. Se a folkcomunicação passou a ser considerada uma disciplina é porque constituiu-se visualizando novos temas e objetos de pesquisa. O objeto de pesquisa desta disciplina situa-se, num primeiro momento, entre o folclore (reinvenção e interpretação da cultura popular) e a comunicação de massa (difusão industrial de símbolos por meios mecânicos ou eletrônicos destinados a audiências amplas, anônimas e heterogêneas).

A folkcomunicação torna-se, portanto, uma disciplina na medida em que passa a demandar métodos atualizados de investigação, ainda que historicamente tais métodos tenham sido capturados da tradição das ciências sociais e posteriormente, a partir dos estudiosos da obra de Beltrão, tenha passado a dialogar com outros modelos teóricos de estudos em comunicação, como os oriundos das ciências da linguagem.

A visão ritual da comunicação, de Carey, também reformula a tradição da pesquisa em comunicação de massa - a mass communication research, como uma das vertentes hegemônicas oriunda da sociologia e da psicologia desenvolvidas nos EUA. A visão ritual vai além da communication research, na medida em que propõe uma concepção de comunicação não como transmissão de informação, mas como uma construção simbólica. No caso, uma construção simbólica não necessariamente com a centralidade da mídia de massa, que tem sido simultaneamente representação e criadora da própria realidade, enfaticamente desde o século XX.

Portanto, para além da pesquisa em comunicação de massa e seus efeitos, e também da pesquisa de mídia, em modelos teóricos que dominaram por muito tempo a pesquisa em comunicação nos EUA com ressonâncias na América Latina e no Brasil, o que Beltrão e Carey fazem com suas propostas de modelos teóricos é fazer avançar as discussões sobre a constituição daquilo a que vem sendo designado, pela comunidade de pesquisadores brasileiros, como ciências da comunicação, que se caracterizam principalmente pelo fato de terem sido pesquisas produzidas em perspectiva interdisciplinar.

Assim, o que se pretende evidenciar é o fato de que a visão ritual e a folkcomunicação contribuíram para consolidar a caracterização historicamente interdisciplinar das ciências da comunicação, com base na abertura para uma amplitude de objetos passíveis de serem pautados e investigados. 
Nos modelos teóricos de Carey e de Beltrão, o que se percebe é a concepção de cultura como a formação de um ambiente que funciona como catalizador da produção de sentido em comum, principalmente em nível comunitário.

As abordagens teóricas de Beltrão e de Carey promovem uma revisão teórico-metodológica na pesquisa em comunicação, na medida em que consideram a possibilidade de inserção de novos objetos de pesquisa e recortes temáticos de investigação - o que inclui expressões culturais em suas virtualidades comunicacionais. Os dois modelos teóricos criam perspectivas de pesquisa que permitem analisar distintas práticas socioculturais em suas dimensões simultaneamente expressivas e comunicacionais.

A partir da inserção dos modelos teóricos dos dois autores no campo de pesquisa comunicacional, as ciências da comunicação tiveram ampliadas suas possibilidades de expansão teórica e metodológica, com os problemas e desafios inerentes a este processo, contribuindo para os debates em nível epistemológico. As demandas acadêmicas e administrativas sobre a disciplinarização da comunicação, tornando-a menos um "campo" e mais uma "disciplina", inclui o quesito: possíveis objetos e métodos próprios de investigação, embora esta propriedade esteja em disputa por distintas disciplinas nas Ciências Sociais e Humanas, e não apenas nas Ciências da Comunicação.

Pretendemos evidenciar dois momentos significativos no desenvolvimento da pesquisa em comunicação, na medida em que se constitui como campo do conhecimento no Brasil. Num primeiro momento, o fato de que a interface entre comunicação e cultura, evidenciada na visão ritual e na folkcomunicação, permitiu um processo de desenvolvimento das pesquisas interdisciplinares que marcaram a emergência das ciências da comunicação no Brasil e nos EUA. Num segundo momento, considerar que a própria interface entre comunicação e cultura, nos modelos teóricos dos dois autores em questão, resultou em abordagens de pesquisa que, ao proporem novos objetos de investigação, para além da comunicação de massa e das modernas práticas midiáticas da chamada indústria cultural, tornaram menos nítido o conceito de mídia, até então centrado no conceito de moderna mídia industrial de massa.

Os modelos teóricos da visão ritual e da folkcomunicação promovem movimentos sincrônicos entre eles, por alinhamento no diálogo com o campo cultural, mas, embora alinhados, também produzem movimentos diacrônicos com relação ao modelo então hegemônico de comunicação de massa que se desenvolve e se consolida ao longo do século XX. Esses movimentos são próprios da autorreflexividade das práticas científicas, na busca constante de adequação e reavaliação de modelos teóricos herdados de outras tradições científicas, no caso a pesquisa de abordagem psicossocial que originou a pesquisa em comunicação de massa nos EUA.

O movimento sincrônico se dá quando os modelos teóricos de Carey e de Beltrão sugerem revisitar as relações comunitárias e interpessoais como práticas comunicacionais, depois da longa hegemonia da pesquisa em comunicação de massa, dada a hegemonia deste próprio modelo comunicacional ao longo do século XX. As práticas da mídia industrial de massa continuam a ser consideradas, mas agora em seu processo de mediação pelas práticas sociais em geral, o que inclui as práticas culturais, em especial as práticas em escala comunitária. O movimento diacrônico, como simultâneo ou conseqüente do movimento sincrônico, refere-se a um princípio de dispersão dos objetos de pesquisa em um sem-número de possibilidades, que incluem desde as conversas pessoais às mais amplas manifestações culturais em escala comunitária ou massiva. 
De qualquer maneira, a visão ritual e a folkcomunicação promovem um avanço na pesquisa em comunicação ao considerarem não apenas a comunicação de massa como modelo industrial e constituinte de um modelo hegemônico de modernização, que são as práticas instituídas do cinema, da imprensa, do rádio e da TV como objetos a serem tematizados nos estudos da área. A partir destas práticas comunicacionais, instituíram-se também como objetos típicos de análise os produtos e os serviços das profissões legitimadas socialmente e ligadas à formação acadêmica do jornalismo, da propaganda, do radialismo, das relações públicas e do cinema.

No âmbito da cultura popular brasileira, segundo Beltrão, e dos processos em que se criam formas simbólicas significativas na cultura de classe média americana, segundo Carey, ganha em evidência a virtualidade da inserção de novos objetos em categorias pertinentes à pesquisa em comunicação, na medida em que os dois modelos teóricos são propostos ao longo da segunda metade do século XX: no Brasil dos anos 1960-70 e nos EUA dos anos 1980, ou seja, em duas experiências distintas de modernização e diferentes condições de acesso aos bens materiais e simbólicos da vida moderna.

Sabe-se que a concepção de uma sociedade de massa na passagem do século XIX ao século XX desestabilizou pesquisas sociológicas como as desenvolvidas pela chamada Escola de Chicago, em sua dimensão de estudos comunitários (COULON, 1995). A emergência e o desenvolvimento da mídia de massa naquele período passaram a constituir a fase da chamada pesquisa em comunicação de massa, que se tornou um modelo teórico hegemônico ao longo do século XX por conta das múltiplas implicações da indústria cultural na economia, na política e na cultura modernas (DEFLEUR; BALL-ROKEACH, 1993, WOLF; 2005).

Pode-se conceber que a relação entre sociedade de massa e comunicação de massa resultou numa das grandes narrativas da Modernidade, notadamente no Ocidente capitalista. O que ficou em segundo plano nessa narrativa foram exatamente as dinâmicas sociais que compreendem as manifestações populares, como indícios de um suposto atraso civilizatório, e os processos simbólicos em que são construídos os modos de ser, pensar e produzir linguagens das grandes massas populacionais em seus banais cotidianos.

Coube às ciências sociais tratarem desses temas em suas variadas linhas de pesquisa e especialidades - na antropologia e na sociologia, principalmente. E, como se pode analisar, foi o diálogo interdisciplinar dessas disciplinas com a pesquisa em comunicação que permitiu o processo de amadurecimento da atividade científica que levou à emergência de modelos teóricos como a visão ritual e a folkcomunicação.

O livro Communication as Culture: Essays on media and society, de James Carey, do qual desconhecemos, até o momento, tradução para o português, está com edição esgotada, segundo as maiores livrarias em atividade no Brasil. Da mesma forma, convém lembrar que os textos de Luiz Beltrão foram forçadamente deixados fora do ambiente acadêmico e científico em tempos de ditadura militar no país, sendo mais bem divulgados apenas a partir dos anos 2000 com a recuperação de sua produção teórica por seus ex-alunos, outros pesquisadores que trabalham a

folkcomunicação como perspectiva teórica e lideranças científicas interessadas no desenvolvimento geral dos estudos em comunicação.

Não é de se estranhar, portanto, o quanto as problematizações teóricas tiveram seu avanço dificultado quando se trata de discutir, de um pretendido ponto de vista da cientificização dos estudos em comunicação, quais seriam seus objetos próprios e quais seriam, portanto, seus 
métodos apropriados de investigação. Algumas das principais discussões sobre a constituição e institucionalização da pesquisa em comunicação no Brasil tem passado, de certa forma insistente e necessária, sobre a amplitude desses objetos aptos a serem enquadrados nos processos de tematização e perspectivação teórica. (WEBER; BENTZ; HOHFELDT: 2002; MARTINO: 2006)

No entanto, deve-se considerar que, desde os anos 1970, com Beltrão, e dos anos 1980, com Carey, foi mais precisamente a revisão teórica proposta pelos dois modelos que ampliou o enquadramento de objetos, na medida em que a visão ritual e a folkcomunicação passaram a tensionar os estudos e pesquisas vigentes, ainda emergentes no Brasil nas décadas de 1970 e 1980, a irem além dos temas da comunicação de massa e das profissões socialmente legitimadas da comunicação social.

A questão que nos parece pertinente, nesses entremeios do pensamento comunicacional, é o fato de que tanto a visão ritual, nos EUA, como o fenômeno da folkcomunicação - e mesmo do folclore e as manifestações populares de modo geral - no Brasil, terem, ainda neste início de século XXI, uma condição minoritária em meio a outras formas culturais, principalmente quando, no bojo da Modernidade, entram em cena a cultura científica e a cultura de massa como modos de percepção hegemônicos da realidade social no Ocidente capitalista.

De modo mais específico, James Carey nos lembra que a visão ritual se encontra numa posição minoritária no pensamento comunicacional americano, seja nos modos de se conceber o que é comunicação nas práticas cotidianas e profissionais ou nos estudos acadêmicos e científicos, diante de um modelo hegemônico, o conhecido e antigo difusionismo, que considera a comunicação enfaticamente como transmissão linear e eficiente de informação no mundo moderno.

No caso da folkcomunicação, as práticas culturais populares, em sua dimensão comunicacional, também configuram, como se pode também analisar de forma análoga, uma condição minoritária, diante de uma visível valorização da cultura erudita e da cultura de massa em meio aos processos de modernização da sociedade brasileira ao longo do século XX, com seus desdobramentos no século $\mathrm{XXI}$, e consequente desvalorização simbólica das práticas culturais relacionadas ao passado, ao antigo e ao obsoleto.

Não é por acaso, portanto, que os objetos mais facilmente enquadráveis nas pesquisas em comunicação historicamente tenderam a ser, de modo mais visível, os relacionados à comunicação de massa, às profissões da comunicação social já instituídas, às instâncias culturais de maior prestígio social e aos processos comunicacionais que usam as mídias reconhecidas como tal (meios mecânicos ou eletrônicos de transmissão de informações).

Assim, cabe perceber, com base na moderna história da pesquisa em comunicação a partir do século XX, que essa prática científica tendeu a se referir, de modo restrito, à pesquisa de mídia, e em especial à pesquisa da mídia de massa. [8]. Mesmo as instâncias profissionais e teóricas que concebiam temas como da comunicação alternativa, da comunicação segmentada e da comunicação popular seguiram a tendência de considerar os processos de comunicação no processo de modernização, ou seja, sendo necessariamente concretizados por algum meio material de emissão de informações.

Nos modelos de Carey e de Beltrão, nem sempre os processos comunicacionais, conforme sugerem os próprios autores, são feitos com base num veículo ou mídia materialmente concebido enquanto tal na modernização do século XX. Na folkcomunicação, a expressão cultural, em sua materialidade 
singular, é, ela própria, a mídia de si, detém uma dimensão comunicacional - caso, por exemplo, e já clássico nos estudos desta disciplina, das expressividades contidas em gestualidades e das canções folclóricas, práticas socioculturais típicas dos folguedos populares. Na visão ritual, as mediações possíveis são os próprios processos simbólicos através dos quais uma comunidade cria sentidos repartidos, "representa a realidade" e "representa para a realidade", tornando possível o vínculo social e as possibilidades de experiência em comum.

Assim, pelo menos desde o final dos anos 1960, quando Beltrão defende sua tese de doutorado sobre folkcomunicação, e dos anos 1980, quando Carey divulga a visão ritual, completam-se respectivamente quase sessenta anos e quarenta e poucos anos, nesta segunda década do século $\mathrm{XXI}$, de produção e divulgação de pesquisa em comunicação, em âmbito científico brasileiro, no qual os objetos de investigação têm sido amplamente concebidos, conforme a abertura sugerida nos dois modelos teóricos em questão.

Conforme se pretende demonstrar neste artigo, o moderno conceito de mídia, a partir da concepção de mídia de massa, restringe-se a uma definição de objetos próprios dos estudos em comunicação como aqueles concebidos ao longo do processo de modernização e, em especial, de transformação do modo de produção capitalista. Nos dias de hoje, as mídias extrapolam a noção de comunicação de massa e de cultura de massa, mas continuam atreladas a uma idéia relacionada diretamente com os processos de inovação tecnológica e, portanto, com uma concepção modernizadora de comunicação.

Quanto a isto, do texto de Carey se obtém uma crítica aos processos que contemplam o moderno modelo de comunicação difusionista que se instala no imaginário americano e mediado materialmente pelos meios de comunicação mecânicos e eletrônicos ao longo do século XX. [9]. Do texto de Beltrão, que localiza veladamente a folkcomunicação nas problematizações de classe social, relembram-se, em termos socioeconômicos, as restritas condições brasileiras de produção, circulação e consumo de informações como uma forma também de crítica à modernidade que insiste em não se instalar no país dos contrastes sociais.

\section{Considerações finais}

O que se percebe na história da pesquisa em comunicação é que os modelos teóricos de James Carey e de Luiz Beltrão promovem um movimento sincrônico entre eles quando propõem a) o enquadramento de novos objetos de pesquisa ligados ao campo da cultura, enfaticamente em nível comunitário e b) novas concepções sobre o que é ou pode ser comunicação no mundo contemporâneo. Simultaneamente, os dois autores, cada qual desenvolvendo um pensamento comunicacional singular, promovem um movimento diacrônico com relação ao modelo hegemônico da tradição da pesquisa em comunicação de massa.

A história evidencia algumas questões relevantes, entre elas o fato de que problematizações teóricas na pesquisa em comunicação relacionam-se, de modo nem sempre muito explícito ou considerado relevante, com questões políticas e mercadológicas. No caso de James Carey e da visão ritual, trata-se, pelo menos para a comunidade de ciências da comunicação no Brasil, da disponibilidade de seus textos, se não em português pelo menos de forma mais consistente em bibliotecas e livrarias do país e nas bibliografias de cursos de graduação e pós-graduação. É razoável afirmar, por exemplo, que exemplares de Communication as culture: Essays on media 
and society circulam em universidades brasileiras, ainda hoje, em forma de fotocópias, o mesmo problema de circulação verificado, até a década de 1990, com os textos de Beltrão. No caso de Luiz Beltrão e da folkcomunicação, sabe-se que o período de ditadura militar inibiu a circulação de sua produção teórica e mesmo constrangeu a divulgação de seu pensamento comunicacional, na medida em que, naquele tempo histórico, possíveis menções a questões de classe tornavam-se motivos de vigilância e repressão ideológica.

A maior divulgação do pensamento comunicacional desses dois autores redimensiona os debates epistemológicos na comunidade científica, mas ainda hoje esse debate é constrangido pelo difícil acesso a textos produzidos no final da década de 1980 (caso de Carey) e nos anos 1960 (caso de Beltrão). Assim, a visão ritual e a folkcomunicação anunciam-se produzindo um distanciamento com relação aos parâmetros oriundos dos estudos em comunicação de massa, do modelo difusor de informações e da moderna concepção tecnológica - e mesmo tecnocêntrica - de mídia. Promovem, com base nessas considerações, uma necessidade de revisão epistemológica nas ciências da comunicação.

A nosso ver, trata-se de se perceber como a abertura interdisciplinar possibilitou a emergência da pesquisa do campo cultural como sendo muito próximo, e mesmo se confundindo, com o campo comunicacional. Contudo, como se percebe nos textos dos dois autores, a cultura ganha uma dimensão comunicacional, o que sugere, como conseqüência destas concepções teóricas, que a comunicação tende a se tornar um paradigma como motor do conhecimento contemporâneo.

A virtualidade de opções nas práticas interdisciplinares resultou num processo de complexificação da pesquisa em comunicação. Engendra-se um campo de disputas em que práticas comunicacionais e midiáticas tornam-se objetos de pesquisa em outras disciplinas e campos do saber. Portanto, o campo instituído da pesquisa em comunicação não está sozinho nessa arena da produção de conhecimento, e não se pode ignorar a presença das nossas alteridades científicas mais próximas, nas ciências sociais e humanas, que também se propõem a investigar os fenômenos da comunicação no mundo contemporâneo.

Outra conseqüência dos modelos teóricos de Carey e de Beltrão é o redirecionamento da pesquisa em comunicação como ciência do comportamento para a comunicação como ciência da cultura, conforme os modelos de estudos teóricos pioneiros propostos por Venício Artur de Lima (2001). No caso da visão ritual, interessa muito mais os modos como são construídos sistemas simbólicos de representação da realidade, considerando que estes sistemas são elementos constituintes da própria realidade. Portanto, a comunicação como cultura, ou a cultura como comunicação, indica a dimensão comunicacional nas mais diversas expressões culturais e sugere a abrangência e a virtualidade de novos objetos de estudos.

$\mathrm{Na}$ folkcomunicação, como os estudos posteriores desta disciplina indicam (BENJAMIN, 1999; SCHMIDT, 2007), interessa verificar como os processos culturais, inclusive os das tradições populares, são reinventados na relação direta com os processos de midiatização, o que nos parece, no caso da cibercultura e das novas mídias digitais, resolver em parte a caracterização que se pretende midiática dos objetos próprios de pesquisa em comunicação.

A nosso ver, se há perdas disciplinares, apesar do histórico interdisciplinar das pesquisas em comunicação, pelo menos no Brasil, é porque, no caso do campo comunicacional, os ganhos tendem a ser paradigmáticos, na medida em que a cultura (em especial uma cultura científica e 
tecnológica) se apresenta como elemento motor da economia do século XXI e a comunicação se insinua como uma das principais características da cultura na contemporaneidade em sua ordem global.

Lembremos de James Carey quando ele suscita para a pesquisa em comunicação nos EUA um redimensionamento e maior relevância do conceito de cultura numa moderna sociedade de consumo, caracterizada, numa perspectiva liberal, por uma busca pela individualidade (que passa a se confundir com insistente individualismo, competição e conflito) e na qual os vínculos sociais configuram-se de forma predominante pelas relações de mercado: é o caso de uma sociedade nacional inventada ao longo do século XX em que a noção de comunidade é tida como utopia a ser construída.

Lembremos, da mesma maneira, de Luiz Beltrão, quando ele suscita para a pesquisa em comunicação no Brasil um redimensionamento do conceito de cultura ao considerar, já na segunda metade do século $X X$, a existência de um país em transição para o qual a experiência de modernização tem sido considerável fator de estranhamento e constrangimento, em especial para os segmentos populares: é o caso em que a noção de comunidade, na forçada e moderna invenção republicana do Estado nação brasileiro, é tida como memória a ser reconstituída ou reinventada.

\section{Referências bibliográficas}

BELTRÃO, Luiz. Folkcomunicação: A comunicação dos marginalizados. São Paulo: Cortez, 1980.

BELTRÃO, Luiz. Folkcomunicação: Teoria e metodologia. São Bernardo do Campo: Umesp, 2004.

BELTRÃO, Luiz. Folkcomunicação: Um estudo dos agentes e dos meios populares de informação de fatos e expressão de idéias. Porto Alegre: Edipucrs, 2001.

BENJAMIN, Roberto. A nova abrangência da folkcomunicação. PCLA, vol. 1, no. 1, out-nov-dez 1999. Disponível em: < http://www2.metodista.br/unesco/PCLA/revista1/artigos3.htm>. Acesso em: 25 mai. 2011.

BENJAMIN, Roberto. Folkcomunicação no contexto de massa. João Pessoa: Editora Universitária UFPB, 2000. Disponível em: <http://www.folkcom2011.com.br/Benjamin_2000.pdf>.

BOSI, Alfredo (org.). Cultura brasileira: Temas e situações. São Paulo: Editora Ática, 2000.

CAREY, James. Communication as culture: Essays on media and society. New York: Routledge, 1992.

COULON, Alain. A Escola de Chicago. Trad. Tomás R. Bueno. Campinas: Papirus, 1995.

DeFLEUR, Melvin; BALL-ROKEACH, Sandra. Teorias da comunicação de massa. Rio de Janeiro: Jorge Zahar Editor, 1993.

FERNANDES, Florestan. O folclore como questão. São Paulo: Martins Fontes, 2003.

LARAIA, Roque de Barros. Cultura: Um conceito antropológico. Rio de Janeiro: Jorge Zahar Editor: 2005. LIMA, Rossini Tavares de. A ciência do folclore. São Paulo: Martins Fontes, 2003.

LIMA,Venício Artur de. Mídia: Teoria e política. São Paulo: Editora Fundação Perseu Abramo, 2001. 
LOPES, Maria Immacolata Vassalo de. Pesquisa em comunicação: Formulação de um modelo metodológico. São Paulo: Edições Loyola, 1990.

MARTINO, Luis C. Abordagens e representação do campo comunicacional. In: Comunicação, Mídia e Consumo, ano 3, vol. 3, número 8, pp. 33-54. São Paulo: ESPM, 2006.

MELO, José Marques de. Mídia e cultura popular: História, taxionomia e metodologia da folkcomunicação. São Paulo: Editora Paulus, 2008.

MELO, José Marques de. Teoria da comunicação: Paradigmas latino-americanos. Petrópolis: Editora Vozes, 1998.

(org.). O campo da comunicação no Brasil. Petrópolis: Vozes, 2008.

MELO, José Marques de; GOBBI, Maria Cristina (orgs.). Gênese do pensamento comunicacional latinoamericano: O protagonismo das instituições pioneiras Ciespal, Icinform, Ininco. São Bernardo do Campo: Umesp, 1999.

ORTIZ, Renato. Românticos e folcloristas e Cultura popular. São Paulo: Editora Olho d'Água, 1992.

PRADO, Luiz Aidar (org.). Crítica das práticas midiáticas: Da sociedade de massa às ciberculturas. São Paulo: Hacker Editores, 2002.

SATRIANI, Luigi M. Lombardi. Antropologia cultural e análise da cultura subalterna. São Paulo: Editora Hucitec, 1996.

SCHMIDT, Cristina. A reprodutibilidade digital na folkcomunicação: A construção de novas linguagens ou o fim do popular. In: Comunicação \& Sociedade, ano 28, no. 47, $1^{\circ}$ sem. São Bernardo do Campo: Umesp, 2007.

TOURAINE, Alain. Crítica da Modernidade. Petrópolis: Vozes, 1994.

TRINTA, Aluísio; POLISTCHK, Ilana. Teorias da comunicação: O pensamento e a prática da comunicação social. Rio de Janeiro: Editora Campus, 2003.

WEBER, Maria Helena; BENTZ, Ione; HOHFELDT, Antonio. Tensões e objetos da pesquisa em comunicação. Porto Alegre: Editora Sulina, 2002.

WOLF, Mauro. Teorias da comunicação. Lisboa: Editorial Presença, 2005.

\section{Dicionários eletrônicos}

Dicionário Eletrônico Houaiss. Disponível em: <www.houaiss.uol.com.br>.

The Free Dictionary. Disponível em: < www.thefreedictionary.com>.

Word Reference. Disponível em: www.wordreference.com>.

\section{Sites na internet}

Jornal Folkcom.

Disponível em: <http://www2.metodista.br/unesco/jornalfolkcom.htm>. Acesso em: 25 jun. 2011.

Portal Eletrônico da Rede Folkcom (Rede de Estudos e Pesquisas em Folkcomunicação). Disponível em: <www.redefolkcom.org.>. Acesso em 25 jun. 2011.

Revista Internacional de Folkcomunicação.

Disponível em: <www.uepg.br/revistafolkcom>. Acesso em: 25 jun. 2011. 


\section{Vídeos}

VER e entender folkcomunicação. Coordenação de José Carlos Aronchi. Direção de Allan Kozlakowski. São Paulo: Uninove (Laboratório da Imagem e do Som), 2005. 1 disco (30 minutos): DVD, son., color. Didático.

\section{Notas}

[1] As traduções ao longo deste texto, apontadas entre aspas com original entre parênteses, são nossas, tendo como ferramentas o Dicionário Eletrônico Houaiss, disponível em www.uol.houaiss.com.br, The Free Dictionary, disponível em www.thefreedictionary. com, e o Word Reference, disponível em www.wordreference.com. Algumas palavras e termos têm tradução precisa em português, outras apenas tradução aproximada.

[2] Literalmente, a tradução seria "sequência de palavras". Dado o contexto na escrita do autor, ao considerar o campo religioso, optamos pela palavra "sermões" [ speeches].

[3] "A ritual view of communication is directed not toward the extension of messages in space but toward the maintenance os society in time; not the act of imparting information, but the representation of shared beliefs". (CAREY: 1992, p. 18)

[4] Ver Carey (1992), em especial o capítulo "A cultural approach to communication".

[5] "... it (social life) also includes sharing of aesthetic experience, religious ideas, personal values and sentiments, and intellectual notions - a ritual order" (CAREY: 1992, p. 34).

[6] “...communication is a symbolic process whereby reality is produced, maintened, repaired, and transformed”. (CAREY: 1992, p. 23).

[7] Autos são conhecidos também como danças dramáticas, praticadas por grupos folclóricos, também conhecidos, em português, como "folguedos".

[8] Ver, por exemplo, SANTAELLA in PRADO (2002, pp. 44-56).

[9] A partir da década de 1990, necessariamente passariam a ser citadas as mídias digitais, que têm demonstrado mudanças e revoluções constantes em sua estrutura tecnológica.

\section{Para citar este artículo}

\section{Gushiken, Y. (2020). Comunicação como ritual (James Carey) e folkcomunicação} (Luiz Beltrão): modelos teóricos na interface com a cultura. Revista Luciérnaga Comunicación. Vol.12 Núm. 23. Pp 13-31. https://doi.org/:10.33571/revistaluciernaga.v12n23a1

OJS. http://revistas.elpoli.edu.co/index.php/luc/issue/archive

Link. https://www.politecnicojic.edu.co/index.php/revista-luciernaga 